DOSSIÊ

\title{
Financeirização contemporânea e precarização do trabalho
}

contemporary financialization and labor insecurity

\section{Tamara naiz da silva*}

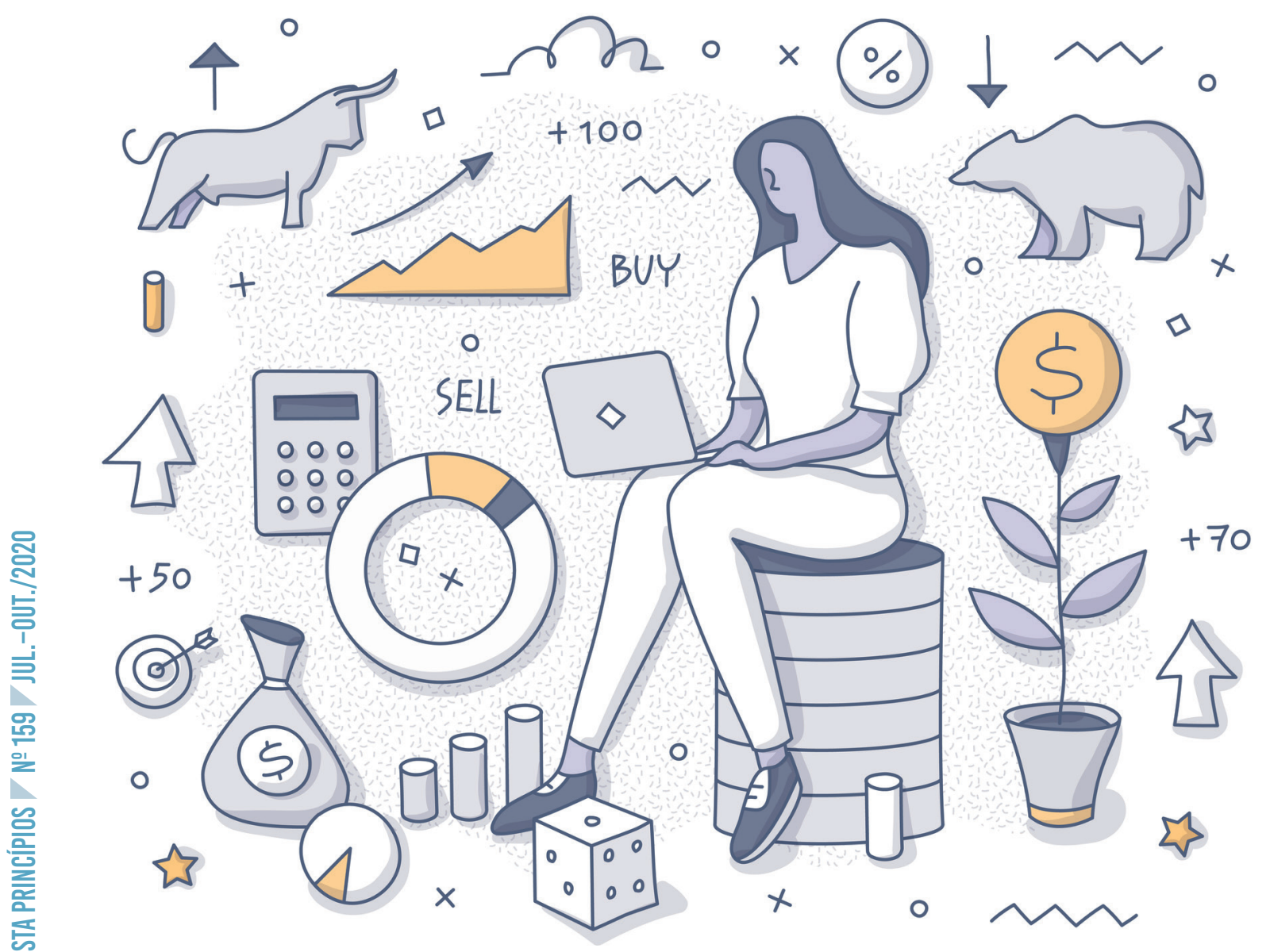




\section{RESUMO}

O tema central do presente artigo é o conflito imanente à relação entre o processo de financeirização da economia mundial e o mercado de trabalho, buscando-se evidenciar suas origens e consequências na atualidade, identificar os antecedentes dessa relação e, além disso, demonstrar que essa é uma relação de tensão, segundo a qual a financeirização precisa necessariamente desvalorizar o trabalho para manter seus níveis de lucratividade, para tal ampliando de modo crescente a superexploração dos trabalhadores e a expropriação dos seus direitos. Discutiremos o conceito de dominância financeira, que nos permite explicar os movimentos do capitalismo contemporâneo e seus consequentes impactos no mercado de trabalho a partir dos anos 1970.

Palavras-chave: Financeirização; Reestruturação produtiva; Neoliberalismo.

\section{ABSTRACT}

The central theme of this article is the inbuilt conflict between the financialization process in the world's economy and the labor market, highlighting its origins and current consequences, identifying their previous relationship. Moreover, we wish to demonstrate that this is a tense relationship, through which financialization must devalue labor in order to keep its profitability levels, increasing the over exploration of workers and expropriating them of their rights. We will discuss the concept of financial dominance, that allows us to explain contemporary capitalist movements and the current impact on labor since the I970s.

Keywords: Financialization; Productive restructuring; Neoliberalism.

\section{INTRODUÇ̃̃̃O}

Da década de 1970 até os dias atuais é a financeirização econômica que influencia decisivamente a dinâmica de crescimento das economias capitalistas em nível mundial. Ela indica o predomínio das operações financeiras sobre as produtivas, evidenciando que ocorre uma mudança na relação entre a produção real e a circulação de valores, o que determina o capital fictício.

Foram diversos os acontecimentos e processos que levaram à mundialização do capital e contribuíram para o domínio das finanças. Em nossa formulação tomaremos as noções de globalização financeira e de mundialização do capital como sinônimas da financeirização, na medida em que, com este conceito, o que buscamos é apreender o modo de ser da riqueza contemporânea, os aspectos de sua dinâmica sistêmica no âmbito dos movimentos internacionais do capitalismo. 
A essência desse padrão de riqueza advém: das alterações dos sistemas monetário e financeiro relativas às mudanças na natureza do dinheiro, do crédito e do patrimônio; da gestão dos bancos centrais sobre a liquidez e taxas de juros; da emergência das corporações produtivas com finanças que são um objetivo em si mesmo; da circulação internacional ampliada dos capitais sob o regime de taxas de câmbio flexíveis; da interação desses movimentos com as restrições impostas às finanças públicas; da desregulamentação financeira; e da condução das políticas de globalização pela hegemonia dos Estados Unidos (TAVARES; MELIN, I997).

\section{A FINANCEIRIZAÇ̃̃o NA CONTEMPORANEIDADE}

Esse processo pode ser compreendido com base em uma contextualização histórica. Para tal iniciamos com Paulani (1992), que investiga as recentes mudanças no sistema monetário internacional do padrão ouro até o neoliberalismo dos anos 1990, análise feita à luz do desenvolvimento dialético do dinheiro, a partir de Marx.

Paulani resgata a lembrança de que, até a Primeira Grande Guerra, a moeda mundial foi a libra, sustentada pelo dinamismo da economia inglesa. Esse lugar de privilégio da libra é enfraquecido com o crescimento rápido de outros países, como os EUA, a Alemanha e o Japão; fora isso, torna-se crescente a incompatibilidade entre a elevação dos salários na Inglaterra e a exportação de grandes volumes de capitais, o que antes era permitido pela evolução favorável dos termos de troca ingleses. Para Paulani, mesmo com a Inglaterra insistindo em manter o padrão ouro e garantindo essa paridade, nesse momento a aparência de ouro da libra não foi suficiente para mantê-la como moeda mundial. Despojada de seu lastro invisível (o dinamismo econômico, agora ameaçado), mesmo mantendo a sua aparência de ouro, a libra não conseguiu sustentar o padrão ouro-libra entre as guerras, o que mostra que a aparência de ouro era apenas ilusão.

No padrão dólar-ouro há uma mudança na relação entre a essência e a aparência da forma dinheiro. No caso do domínio da libra, a aparência do dinheiro é a de uma mercadoria verdadeira (o ouro), e com isso a essência da aparência do dinheiro fica dissimulada (em uma "aparência da aparência"), "porque tudo se passa como se o ouro fosse a única aparência adequada, ou seja, funcional, à forma dinheiro" (PAULANI, I992, p. I73).

É justamente na mudança do padrão ouro-libra para o padrão dólar-ouro, quando o dólar assume o papel de moeda de reserva internacional, que essa aparência dissimulada do dinheiro se perde e a essência da aparência do dinheiro é revelada. Prossegue a autora:

Ele tem de ser aparentemente mercadoria, mas não precisa aparentar nenhum substrato objetivo; basta que ele encarne o objeto que, por excelência, tenha a potencialidade de imobilizar o valor de troca, basta que ele se mostre como o porto seguro onde se abrigar das tempestades que sua própria essência formal pode ajudar a desencadear (PAULANI, 1992, p. I73). 
Se antes, com o padrão ouro, era como se o dinheiro devesse ser o valor em pessoa (uma mercadoria, fruto do trabalho humano), materializado num substrato palpável (as barras de ouro), a partir daqui o padrão dólar mostra que isso não é mais necessário: tornando-se apenas um signo do valor (o papel moeda), que não pertence ao campo das mercadorias, cumpre o papel de forma materializada do valor. De modo que, após o fim do padrão ouro, as reformas monetárias e bancárias do New Deal tinham como objetivo libertar a moeda dos limites físicos que o lastro no ouro representava.

Para Paulani, foi o dinamismo tecnológico dos EUA, superior ao das demais potências, que garantiu a hegemonia da moeda estadunidense como âncora lastreadora do grande crescimento do capitalismo mundial, de três décadas, durante o período de Bretton Woods. Ainda no período fordista, o avanço tecnológico e produtivo foi fundamental para que o dólar pudesse ganhar autonomia em relação ao ouro, um "dinheiro corpóreo". Com a reestruturação produtiva que alcança o mundo pós-fordismo, a tecnologia se torna cada vez mais importante, pois cria uma enorme capacidade produtiva, mas põe o sistema sob o risco permanente de uma crise de superprodução, de modo que o capital busca saídas para se remunerar fora do processo produtivo, fortalecendo os circuitos de acumulação financeirizada, não corpórea, desligada da produção.

Na década de 1960 os Estados Unidos passam a emitir dinheiro para financiar a idade do ouro, assim como sua própria posição hegemônica no mundo ${ }^{1}$. Apesar do contexto monetário internacional de expansão de liquidez, havia latente uma ruptura, pois aquela liquidez só era possível graças aos déficits do balanço de pagamentos². O sistema financeiro estadunidense ${ }^{3}$ começava a ser internamente alterado por uma práxis privada e pública de caráter liberalizante e estimuladora da especulação. Ao mesmo tempo que o déficit público e a inflação colocavam em dificuldades a gerência das políticas fiscal e monetária, que deveriam tentar manter sob controle o déficit, os gastos governamentais em programas sociais, infraestrutura e programas militares deveriam ser preservados.

Esse conjunto de questões ${ }^{4}$ determinou já na primeira parte da década de 1970 o fim da prosperidade da idade do ouro e conformou, paulatinamente, as bases do novo padrão de riqueza que vinha se configurando.

De volta à análise de Paulani, ela afirma que hoje a busca de um substrato objetivo para o valor é inútil, o que é mostrado pelas flutuações descontroladas das taxas de câmbio, de juros, dos preços das matérias-primas e produtos industriais e dos

1 Esses gastos incluíam desde infraestrutura e programas sociais, além de internacionalização das corporações e dos bancos, até programas militares e a guerra colonial no Vietnã (BRAGA, 1997, p. 200201).

2 Fator esse que terminaria por minar a "confiança" no dólar como reserva de valor conversível em ouro.

3 Que tinha até então a estabilidade baseada no aparato regulatório montado após a crise dos anos 1930 e reforçado no pós-guerra.

4 Somado à decisão, tomada unilateralmente pelo governo dos EUA em 1971, de pôr fim à conversibilidade do dólar em ouro. 
ativos em geral após a década de 1970. A crise evidenciada pelas baixas taxas de crescimento em todo o mundo após 1970 tem, para a autora, um caráter peculiar, pois a essência puramente formal do dinheiro é "dolorosamente revelada". Assim, se na passagem do padrão ouro-libra para o padrão dólar-ouro o dinheiro perde a aparência de sua aparência, ficando só com a essência dela ${ }^{5}$ (5) (ele não precisa ser mercadoria real, mas apenas ter aparência de mercadoria, isto é, figurar como reserva segura do valor), na crise do padrão dólar-ouro que se configura a partir dos anos 1970 o dinheiro perde também a essência de sua aparência: quando os EUA abandonam a vinculação do dólar ao ouro, ele sequer aparece como mercadoria. Escreve assim a autora que:

A dança dos valores no mercado internacional nas últimas duas décadas expressa justamente a busca, pelo sistema, de uma aparência condigna, a busca da mercadoria absoluta — que agora não se sabe mais onde está, ainda que o dólar americano, bem ou mal, venha conseguindo se sustentar como padrão internacional do valor (PAULANI, 1992, p. I76).

Deve-se destacar que, para a autora, pelo fato de o dinheiro mundial também ter se tornado mero signo do valor, o sistema foi levado a uma instabilidade significativa: "ao restar apenas como a aparência de sua essência, a essência de sua aparência não convence mais ninguém e a incerteza pode não ter mais onde se abrigar" (PAULANI, I992, p. I77).

Essa etapa conhecida como mundialização do capital (CHESNAIS, 1998a) se inicia com a busca do capital de se liberar dos entraves à sua valorização, sobretudo das obrigações definidas nas políticas de bem-estar do pós-guerra. O que evidencia um ganho de força do mecanismo de mercado.

Sobre isso, Mollo observa:

Daí o termo neoliberalismo para designar a filosofia econômica que o sustenta, embora isso não queira dizer retirada do Estado, uma vez que a desregulamentação, ou a redução da intervenção econômica estatal, se fez com o beneplácito dos governos, não apenas porque realizaram a liberalização das economias, mas se valeram dela na venda dos seus títulos de dívida que tiveram e têm papel importante no desenvolvimento dos mercados financeiros mundiais (MOLLO, 20II, p. 490).

5 Assim, o dinheiro tem, em sua essência, um caráter meramente formal, mas na sua aparência o dinheiro não figura assim, ele deve aparecer como uma mercadoria, como reserva segura do valor, da riqueza, ainda que essencialmente não o seja, porque sua medida não é invariável. Desse modo, o dinheiro é um objeto contraditório, pois ele é e não é mercadoria. Marx compreende então que o dinheiro enquanto meio de pagamento traz uma contradição, que estoura no momento das crises, pois, se em sua essência ele é pura forma, na aparência ele tem que ser mercadoria, no sentido de que deve ser reserva do valor, encarnação deste, e esta contradição entre essência puramente formal e a necessária aparência de mercadoria, apontada por Paulani, se evidencia nos momentos de crise, quando todos querem dinheiro vivo em mãos, mas percebem que ele também não é o que aparece, não é a reserva segura da riqueza que se espera (Teixeira, 2007; Paulani, 1992). 
A liberdade cada vez maior dos mercados, mormente desde os anos I980, aguçou a concorrência entre os capitais e deu início à desregulamentação dos mercados financeiros de forma geral, o que impulsionou a busca de lucros rápidos, em grande parte especulativos, e uma enorme gama de inovações financeiras cada vez mais arriscadas. Foi esse processo que permitiu grande progresso do capital fictício (MOLLO, 20II, p. 490).

Para Mollo, o que teria tornado possível tal desenvolvimento durante essas décadas foi

O volume enorme de recursos provenientes da junção dos mercados de crédito no mundo, que ocorreu com a liberalização das economias, mais particularmente com a abertura ao movimento de capitais, a desregulamentação generalizada dos sistemas financeiros, mudanças dos sistemas tributários e as inovações tecnológicas. Essa massa enorme de recursos, embora tenha sido aplicada nos vários países, concentrou-se em poucos mercados desenvolvidos e em menor medida em alguns mercados emergentes (MOLLO, 2OII, p. 489).

Foi esse enorme volume de capital em mercados específicos que levou a um grande descolamento do valor dos ativos financeiros em relação ao valor do capital real que dava origem às rendas, estas fundamentais para manter a demanda de títulos e sua decorrente valorização.

Para obter essa massa de recursos necessária, e também compensar o descolamento, as empresas privadas começaram um processo de reestruturação produtiva e os Estados adotaram políticas de austeridade dos orçamentos públicos, com consequências negativas sobre o nível do emprego e do gasto social.

Claudio Salvadori Dedecca observa que houve uma incapacidade por parte dos trabalhadores em responder coletivamente com uma alternativa ao processo de ajuste das economias capitalistas, que seria inevitavelmente marcado pelo desemprego e pelo recrudescimento da desigualdade, pois, ao mesmo tempo que o declínio do longo ciclo de crescimento anterior criou uma situação de grande pressão econômica, também recompôs o poder de barganha das empresas na contratação de trabalho. (DEDECCA, 20Io, p.9).

Diante da crise do emprego, os Estados passaram a chamar para si a promoção de reformas na regulação do contrato e das relações de trabalho, iniciativa que interessava particularmente às empresas.

Enquanto a desregulamentação do trabalho era promovida, as fronteiras financeiras das economias desenvolvidas eram abertas, restaurando-se uma maior liberdade de movimentação de capitais entre países. Diante do contexto de crescente incerteza quanto ao futuro do mercado de trabalho e do próprio Estado de bem-estar social, o interesse das famílias de maior renda em programas de previdência privada e nos fundos de capitalização foi aumentando; ao mesmo tempo, isso ensejou um mercado potencial a ser explorado pelas instituições financeiras. 


\section{As transformações no modo de produção determinadas pelas inovações técnicas e organizacionais foram progressivamente corroendo a densidade do contrato de trabalho por tempo indeterminado e provocando a instabilidade do trabalho assalariado. Isso aconteceu junto com a terceirização e a polivalência, praticadas sob a navalha da ameaça recorrente do progresso técnico sobre a condição de emprego, que deram às empresas um poder importante de gestão da mobilidade do trabalho segundo seus interesses}

Destarte, é perceptível que a partir da década de 1970 a crise da economia capitalista em nível mundial, ao resultar no problema do emprego e em dificuldades de financiamento do Estado, acabou por abrir os caminhos para uma reativação do processo de financeirização do sistema, cujo desenvolvimento acabou marcado pelo agravamento da desigualdade econômica. E não poderia ser diferente, pois aquele processo dependia do desgaste do padrão de regulação que havia garantido a redução dos níveis de desigualdade nas décadas anteriores.

\section{DOMINÂNCIA FINANCEIRA E INSTABILIDADE SISTÊMICA}

Seguiremos agora buscando evidenciar a possibilidade de dominância da valorização financeira e do capital portador de juros, elaboração que não está evidente na obra de Marx e que é passo fundamental para este artigo, já que partimos da premissa de que na atualidade estamos diante de uma nova fase do capitalismo na qual o capital financeiro estaria determinando a lógica do processo de reprodução ampliada do capital.

De modo que procuraremos apresentar aqui alegações que colaborem na defesa da tese da existência na atualidade de um regime de acumulação com dominância financeira.

Na leitura de O Capital podemos observar que, em diversas ocasiões, Marx apresenta a possibilidade de autonomização da valorização puramente financeira, com a formação de bolhas especulativas de capital fictício — o autor localiza aí a origem das 
crises financeiras do capitalismo. Essas crises derivam, para ele, de um "descolamento" da esfera financeira com relação ao processo de valorização e à criação de mais-valia, que ocorre na esfera produtiva. De modo que a valorização financeira depende de uma extração ainda maior da mais-valia no processo produtivo.

Todavia, em Marx esse descolamento nos é apresentado apenas como forma de manifestação da crise no processo de reprodução do capital produtivo, como resultado da expansão da acumulação produtiva, e quando esta perde fôlego - com a queda da taxa de lucro, a superprodução etc. - , advém a explosão da bolha e a crise financeira.

É preciso observar que em Marx as ocorrências da autonomização da esfera financeira são pontuais e temporárias. Ele não apresenta uma elaboração que nos indique a possibilidade de uma "dominância financeira" perene do processo de valorização; pelo contrário, o autor salienta o caráter fetichista e ilusório da valorização financeira. De modo que buscaremos aqui apoio em alguns autores marxistas contemporâneos para desenvolver a possibilidade da autonomia da esfera financeira até a dominância financeira.

Contudo, cabe partirmos da definição de dominância financeira. Para Rodrigo Teixeira, não se trata de uma questão puramente quantitativa, "no sentido de uma dominância da valorização financeira, ou seja, de que a valorização financeira teria sobrepujado a valorização na esfera produtiva em termos quantitativos", pois, mesmo que seguramente acompanhe a noção de dominância financeira, a mudança quantitativa na estratégia de valorização dos capitais ${ }^{6}$ não é sua principal característica (TEIXEIRA, 2007, p. 59).

Marx defende a ideia de que a autonomia da esfera financeira é ilusória, já que o capital portador de juros se alimenta, assim como o capital comercial, da criação de valor que só se realiza na reprodução real do capital, ou seja, na esfera produtiva. De modo que a esfera financeira só pode ser consumidora de excedente e não produtora, mesmo que ela possa ser considerada, tal como o capital comercial, como "indiretamente produtiva", já que o crédito impulsiona a acumulação. Portanto, se faz necessário que exista um processo produtivo do qual a esfera financeira se alimente.

Paulani (2004) atesta então que, em função da lógica de valorizar-se mantendo a máxima liquidez, o capital financeiro passa a dominar todo o processo de valorização, inclusive na esfera produtiva: a sentença mais apropriada para esse fenômeno seria dominância financeira da valorização.

Dominância financeira da valorização afigura-se um termo mais adequado do que dominância da valorização financeira, pois enquanto o último refere-se a momentos ou fases na história do capitalismo em que a valorização rentista se exacerba e se sobrepõe à valorização produtiva de um modo insustentável no longo prazo, o primeiro diz respeito à etapa corrente do capitalismo, na qual a importância e a dimensão dos capitais e da valorização financeira

6 Mudança que consistiria em sair do ciclo do capital produtivo, D - M - D', para o ciclo do capital portador de juros, D - D'. 
combinados à peculiar forma assumida pelo sistema monetário internacional fazem com que a lógica da valorização financeira contamine também a esfera produtiva, gerando um novo modo de regulação adequado ao regime de acumulação financeira (PAULANI, 2004).

Todavia, essa dominância financeira debilita o processo de valorização na esfera produtiva. Trataremos disso adiante.

Chesnais $(2005)^{7}$, um dos principais teóricos defensores da tese da dominância financeira, afirma que estamos diante de um novo binômio regime de acumulação/ modo de regulação, que ele chama de regime de acumulação mundializado com dominância financeira. O que caracteriza esse regime é a dominância das finanças, que não são mais apenas intermediárias, mas determinam o direcionamento do capital e, assim, a própria natureza da acumulação.

Chesnais, situa o regime monetário e financeiro como a forma institucional mais importante para compreender o atual regime de acumulação com dominância financeira:

O "regime de acumulação com dominância financeira" designa, em uma relação direta com a mundialização do capital, uma etapa particular do estágio do imperialismo, compreendido como a dominação interna e internacional do capital financeiro. A hipótese de um regime de acumulação submetido a uma finança que se poderia constituir - momentaneamente — como uma potência econômica e social "autônoma", frente à classe operária como também a outras frações do capital, foi vislumbrada por Marx. Ele a associa ao fetichismo particular do dinheiro, levado à sua forma extrema (CHESNAIS, 2003, p. 46).

Para o autor, esse novo regime tem relação intrínseca com a chamada globalização, que ele renomeia mundialização financeira: "A 'mundialização financeira' possui, de modo evidente, a função de garantir a apropriação, em condições tão regulares e seguras quanto possível, das rendas financeiras - juros e dividendos - numa escala mundial." (CHESNAIS, 2003, p. 52)

Chesnais, partindo da crise do regime fordista de acumulação, no início da década de 1970, mostra como se engendrou ali um novo regime de acumulação, caracterizado pelo predomínio da forma do capital portador de juros (D - D') na acumulação capitalista, motivado pela queda da taxa de lucro, que deixou uma massa de capitais ociosos em busca de valorização, e facilitado pela revolução tecnológica na microeletrônica e na informática, bem como pelas mudanças institucionais que promoveram a liberalização e desregulamentação dos mercados financeiros internacionais. Esse processo se deu de forma indireta a partir dos anos 1960 (com o mercado

7 autor tem seu arcabouço teórico na Escola da Regulação. Para os regulacionistas, o regime de acumulação corresponde à forma como se dá a acumulação capitalista propriamente dita, e o modo de regulação corresponde ao conjunto de normas, instituições, ideologias e costumes adequados ao regime de acumulação e que lhe garantam estabilidade. 
de euromoedas), e de forma direta na década de 1980, com os governos conservadores de Margaret Thatcher no Reino Unido e Ronald Reagan nos EUA adotando medidas explícitas para conter o que alguns autores chamam de "repressão financeira".

Em todos os países o domínio das finanças liberalizadas e desregulamentadas traz prejuízos ao crescimento econômico e ao nível de emprego. Chesnais assegura que o predomínio da forma do capital portador de juros tem efeitos perversos do ponto de vista do crescimento econômico e da distribuição da renda, pelo próprio funcionamento da lógica da acumulação rentista, o que explicaria o baixo crescimento mesmo nos países centrais. No que diz respeito ao crescimento, os capitais que poderiam ter aplicação produtiva, em face da alta mobilidade e das altas taxas de juros atuais, bem como das possibilidades de ganhos especulativos trazidos pelas inovações financeiras, acabam ficando circunscritos a uma esfera de valorização puramente financeira, onde conseguem ao mesmo tempo elevada rentabilidade e máxima liquidez ${ }^{8}$ (8).

Outra questão relevante tratada por Chesnais é a alteração nos regimes de previdência, em favor dos regimes de capitalização, que criaram os investidores institucionais, os quais estão entre os maiores agentes dos mercados financeiros atualmente: os fundos de pensão. $\mathrm{O}$ autor salienta a fragmentação da identidade de classe causada por esses investidores institucionais, que "fazem de seus beneficiários indivíduos fragmentados, cuja personalidade social está cindida: de um lado, a de assalariados e, de outro, a de membros auxiliares das camadas rentistas da burguesia" (CHESNAIS, 2002, p. 52).

Segundo Chesnais, esse regime de propriedade patrimonial cria uma distância da finança com relação às atividades de produção e de investimento (incluindo a tecnologia), que vai na direção oposta à forma funcional do investimento produtivo. Verifica-se um processo de centralização de capital ainda mais forte do que o descrito por Lênin em seu livro Imperialismo: fase superior do capitalismo, com o processo de fusões e aquisições em escala global. Mas agora, ao contrário, a finança teria conseguido alojar a "exterioridade da produção" no cerne dos próprios grupos industriais.

Teixeira assinala que é justamente essa exterioridade da produção que faz com que os interesses de longo prazo dos grupos industriais sejam substituídos pela lógica da busca de rentabilidade de curto prazo dos acionistas, com as pressões para o aumento do pagamento de dividendos e a consequente queda dos lucros retidos. Ao mesmo tempo, para atender a essas exigências de rentabilidade, as empresas exercem o novo poder administrativo contra os assalariados, por meio das transformações no mundo do trabalho visando à redução dos $\operatorname{custos}^{9}$, o que leva a uma queda da participação relativa dos salários na renda.

8 Como vimos anteriormente, os títulos e ações são a forma do capital portador de juros que se convertem em capital fictício, tanto no caso da dívida pública, que não representa capital algum (e que é, segundo Marx, um "não capital"), como no caso das ações que, apesar de representarem um capital real, têm seu valor determinado independentemente, em termos relativos, do ciclo produtivo do qual esse capital participa, o que abre espaço para as estratégias de ganhos puramente especulativos por parte dos proprietários.

9 Tais transformações incluem a reengenharia, o downsizing e uma maior flexibilização (leia-se precarização) do trabalho, com a terceirização, o trabalho em tempo parcial, o temporário etc., e a deslocalização e subcontratação internacional. 
Temos então uma lógica de acumulação na qual, ao mesmo tempo que se verificam poucos incentivos ao investimento produtivo e atonia do crescimento econômico, há uma redistribuição funcional da renda em detrimento dos salários.

Buscaremos agora, com base em Frontana (2000), caracterizar o novo binômio regime de acumulação/modo de regulação, chamado pelo autor de regime de acumulação com dominância financeira e caracterizado pela primazia das relações financeiras na dinâmica econômica.

Para o autor, essa primazia se dá segundo três planos: I) na orientação financeira das políticas econômicas: a gestão monetária, fiscal, financeira e cambial fica condicionada à lógica rentista, reduzindo a capacidade do Estado de estimular a demanda agregada e realizar investimentos e políticas distributivas. Acrescentaríamos a isso a redução da autonomia da política econômica doméstica, num contexto de livre mobilidade de capitais, criando um ambiente altamente propício à especulação; 2) na conduta rentista crescente de segmentos sociais, sobretudo as famílias de renda média e alta, que buscam aumentar suas rendas atuais ou garantir suas aposentadorias por meio dos rendimentos financeiros; 3) nas estratégias das empresas do setor produtivo, que buscam cada vez mais as rendas financeiras. Poderíamos acrescentar a estratégia dos bancos, que contraem o crédito e buscam os ganhos de tesouraria, operando nos mercados de títulos da dívida pública, câmbio e derivativos. O sistema financeiro perde assim seu papel de financiar o desenvolvimento econômico.

As decisões no campo industrial passaram a depender de uma multiplicidade de variáveis financeiras, sobretudo da evolução das taxas de câmbio e de juros e de suas diferenças nacionais. O resultado, graças à difusão mundial de medidas de liberalização, desregulamentação e estímulo às inovações financeiras, foi um notável aumento da importância das operações puramente financeiras dos grupos industriais multinacionais, isto é, uma deformação dos balanços das empresas não financeiras, em benefício dos ativos financeiros (imobilizações ou aplicações financeiras) e em prejuízo do investimento produtivo de longo prazo (TEIXEIRA, 2007, p.68).

Há, portanto, uma subordinação das atividades produtivas dos grandes grupos industriais à lógica financeira, rentista e "curto-prazista", que passa a dominar a gestão da riqueza no novo regime de acumulação - um regime que, num contexto mais amplo, estabelece uma clara hierarquização das relações econômicas, pela qual cabe às finanças e aos mercados financeiros ocupar a cúpula do sistema, orientando as ações e os movimentos do capital que se dedica à produção ou à comercialização (TEIXEIRA, 2007, p. 68).

Frontana observa que a financeirização dos grandes grupos industriais não se dá apenas no âmbito das atividades, ela também ocorre no âmbito da propriedade e do comando:

A presença cada vez maior dos investidores institucionais (agentes mais poderosos da esfera financeira) como acionistas controladores das empresas do setor produtivo e a implementação dos princípios e critérios de gestão do 
corporate governance traduzem, muito mais do que a multiplicação das atividades financeiras dos grupos, o predomínio da "lógica financeira" sobre a "lógica produtiva" que caracteriza o regime de acumulação sob dominância financeira, o comando crescente da esfera financeira sobre a repartição e a destinação da riqueza criada no setor produtivo (FRONTANA, 2000, p. I86).

Sobre isso, Harvey estabelece a relação entre as transformações recentes na esfera financeira e as ocorridas na esfera produtiva, evidenciando que na fase atual do capitalismo estaria se configurando um regime de acumulação flexível. Dessa forma, de modo oposto à rigidez do fordismo, a acumulação flexível caracteriza-se pela busca de valorizar o capital mantendo a máxima flexibilidade. Na esfera produtiva, a flexibilidade aparece tanto no capital variável (fim dos direitos trabalhistas e polivalência do trabalhador) quanto no capital constante (com as plantas flexíveis possibilitadas pela microeletrônica e a robótica).

No início dos anos 1970 houve um momento de crise, como aqueles que Marx descrevera, quando a busca pela liquidez é grande, pois, como já falamos, nos momentos de incerteza os capitalistas buscam a liquidez porque ela também significa flexibilidade, aliás a máxima flexibilidade. Dessa forma, a expansão do capital portador de juros é uma maneira de o capital adquirir flexibilidade, permanecendo em sua forma líquida, como capital monetário.

Adentrando a abordagem sobre a acumulação flexível de Harvey, a ênfase está na flexibilidade do capital produtivo, que se reflete tanto no capital constante quando no capital variáve ${ }^{10}$. Como se sabe, Marx distingue o capital variável, composto pelo capital que compra a força de trabalho (é variável porque cria valor) do capital constante (que não cria valor, mas tem apenas seu valor transferido para o produto final). O capital constante divide-se em dois tipos: o capital circulante, que são as matérias-primas e outros insumos produtivos totalmente consumidos no processo produtivo, e o capital fixo ${ }^{11}$, que são as máquinas e equipamentos, cujo valor é transferido parcialmente às mercadorias ao longo do tempo, de acordo com certa taxa de depreciação.

Tais ações na esfera produtiva visam à redução de custos e à flexibilização da oferta, para adequá-la às condições da demanda, mantendo no nível mínimo os estoques de insumos e matérias-primas e de produtos semiacabados, de modo a reduzir a "ociosidade" do capital. A redução de custos é obtida com o "enxugamento" dos

10 No tocante ao capital variável, a flexibilidade tem sido obtida pela precarização do trabalho (reformas na legislação trabalhista, com perda de direitos anteriormente conquistados, terceirização, trabalho temporário e parcial, informalidade etc.) e pelas novas formas de gestão, que envolvem maior participação e autonomia do trabalhador, exigindo dele agora polivalência e nível educacional elevado, para que se adapte às novas necessidades das plantas flexíveis.

11 No tocante ao capital fixo, o que ttrouxe a flexibilidade foi a revolução tecnológica que gerou as plantas flexíveis, possibilitadas pela mecatrônica (aplicação da microeletrônica e da informática à mecanização), em oposição ao paradigma tecnológico anterior, fundado na eletromecânica. As plantas flexíveis podem produzir diferentes produtos, adequando-se melhor à demanda, diferentemente das plantas fordistas, que eram especializadas num único produto e centradas nos ganhos de escala. 


\section{Financeirização, fragmentação do trabalho e desigualdade social são partes de um mesmo conjunto e fundamentam o regime de regulação econômica e social construído a partir do final dos anos 1970}

postos de trabalho e dos postos de gerência, bem como com as técnicas de controle da qualidade, redução de desperdícios e diminuição dos estoques. A redução de recursos ociosos é obtida também pela flexibilização do trabalho, para que a empresa não precise continuar pagando salários nos momentos de desaquecimento da demanda nem incorrer em altos custos para se desfazer dos trabalhadores, e pelas plantas flexíveis, que permitem ajustar a produção à demanda sem deixar um imenso estoque de capital fixo ocioso.

De modo que ocorre uma ligação intrínseca entre as transformações na esfera da produção e as que se processam na esfera financeira, mas tal conexão se estabelece sob a dominância financeira, cuja lógica comanda a própria esfera produtiva.

Apesar de as noções de regime de acumulação e modo de regulação remeterem a uma ideia de estabilidade, a característica central desse novo regime é, para Frontana, a interiorização da instabilidade:

Longe de ser um resultado indesejável de seu funcionamento, a instabilidade, que é intrínseca às economias monetárias e ao processo de acumulação, parece ter sido integralmente incorporada como elemento constitutivo da lógica operacional do novo binômio que regula o sistema capitalista. Para preservar a sua institucionalidade monetário-financeira e garantir sua coerência interna, o regime de acumulação sob dominância financeira depende e se alimenta dessa instabilidade e da atmosfera especulativa e volátil a ela associada. Em outras palavras, a instabilidade foi endogeneizada pelo novo binômio e se apresenta como um componente estrutural necessário para o seu funcionamento (embora constitua, também, a sua principal contradição). Os choques, sobressaltos, turbulências financeiras periódicas e crises financeiras localizadas ou disseminadas, fenômenos resultantes da permanente instabilidade monetária e financeira e do caráter volátil dos mercados, além de constituírem uma característica historicamente marcante do novo binômio, parecem ser também parte imprescindível de sua lógica acumulativa. São esses fenômenos que oferecem oportunidades de se obterem ganhos (e perdas) extraordinários no sistema financeiro mundializado (um sistema que, pelas suas características especulativas, cada vez mais se assemelha a 
um grande "cassino" financeiro global). Sem eles, a concentração e a centralização do capital em benefício da esfera financeira seriam mais lentas, quando não insustentáveis (FRONTANA, 2000, p. 317).

É preciso destacar que essas mudanças todas estão, como aponta Robert Guttmann, apoiadas politicamente em uma determinada base social:

Na falta de um regime monetário capaz de se impor aos agentes econômicos, a política econômica tem sido ditada, em grande parte, pelas instituições financeiras privadas, que atualmente estão em condições de impor ao restante da sociedade as suas opções favoráveis a uma inflação baixa, altas taxas de juros reais e desregulamentação de todos os mercados. Essas prioridades de política econômica tendem a ser apoiadas por instituições ou por setores sociais de grande influência política: os bancos centrais independentes e as administrações financeiras de grandes empresas industriais, que detêm importantes carteiras de títulos e divisas; a geração do baby boom do pós-guerra, começando a se preocupar com seus sistemas de aposentadorias por capitalização; e os setores de classe média alta, detentores de poupança, que lucram com a liberalização financeira, porque agora têm acesso a formas de aplicação que só eram acessíveis às grandes fortunas. Os políticos que viraram as costas a essa coalizão, favorecendo outros objetivos políticos, têm sido castigados com grandes fugas de capital até serem obrigados, através de graves crises de câmbio, a mudar de política." (GUTMANN, I998, p.87).

Diante do cenário traçado, concluímos, na companhia de Teixeira, que, salvo se a correlação de forças mudar a ponto de provocar a reversão das medidas liberalizantes que colocaram o capital portador de juros no centro das relações sociais, a economia mundial tende a apresentar indefinidamente crescimento baixo, elevado desemprego, instabilidade crônica e a continuidade do processo de concentração da renda em curso, com suas consequências perversas como o aumento da exclusão social e de amplas áreas do globo dos benefícios do imenso progresso tecnológico das últimas décadas (TEIXEIRA, 2007, p. 72).

\section{PRECARIZAÇÃO HUMANA E DESIGUALDADE SOCIAL: O OUTRO LADO DA FINANCEIRIZAÇ̃̃o}

É possível depreender de nossos estudos que a desestruturação da sociedade salarial, ao enfraquecer o regime de regulação, possibilitou a redefinição das políticas e dos mecanismos de distribuição do excedente produtivo - o que trouxe insegurança para os diversos setores da sociedade, que procuraram recompor os seus interesses financeiros. No interior da organização social, a razão financeira foi ganhando espaço, em detrimento da produtiva, processo esse reforçado pela desvalorização do trabalho na sociedade capitalista contemporânea. As complicações encontradas pelo pro- 


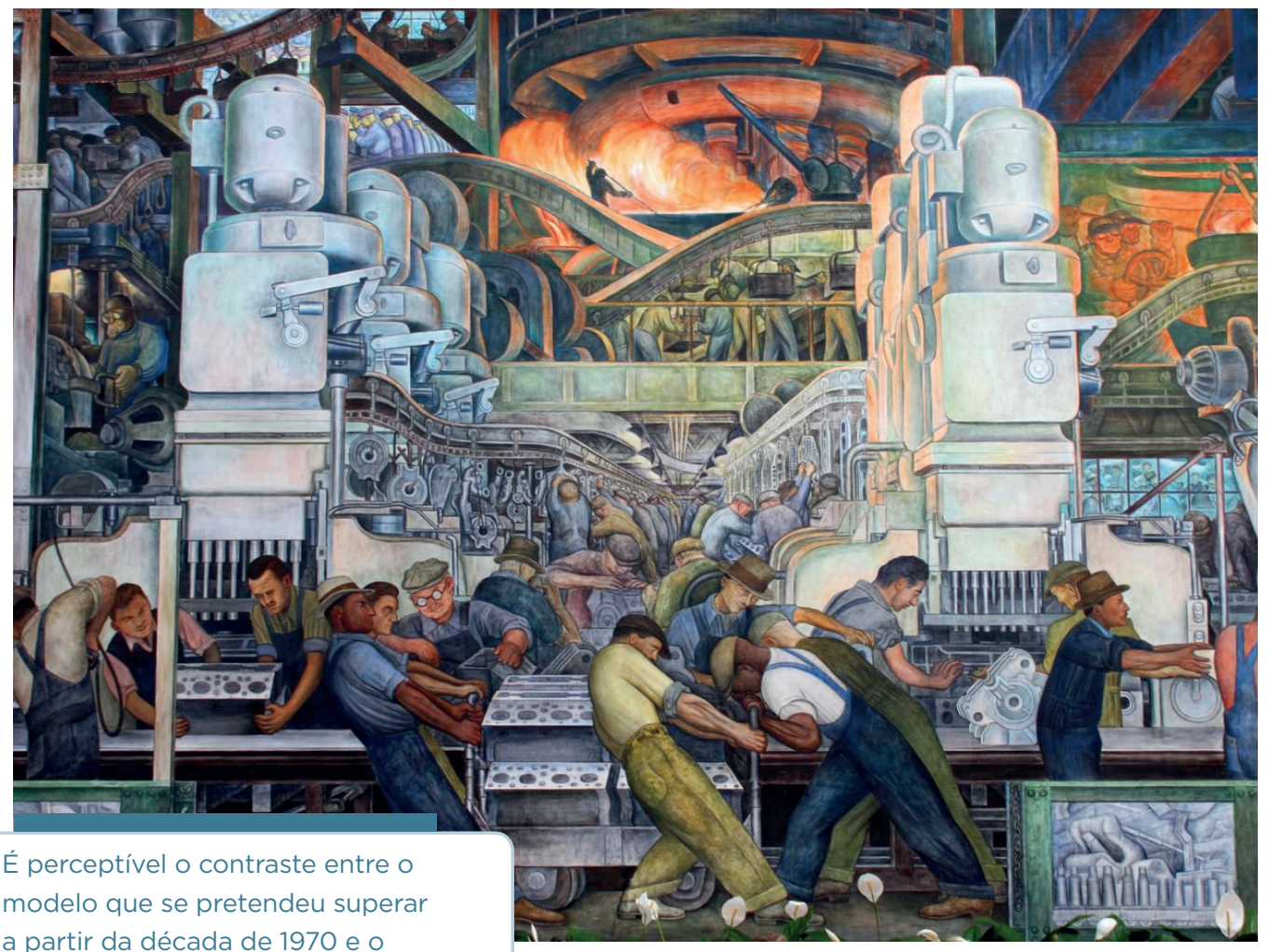

a partir da década de 1970 e o

novo, que se erigiu sob o signo da

financeirização

Mural do artista mexicano Diego Rivera no Detroit Institute of Arts (DIA) (Divulgação)

gresso capitalista foram enfrentadas com a desvalorização progressiva do trabalho, desestruturando as dimensões que haviam caracterizado o regime de regulação do após-guerra.

Como resultado dessa dinâmica de desvalorização do trabalho, houve um recuo dos salários, tanto na renda das famílias quanto no produto nacional. "De modo progressivo os salários foram perdendo importância no processo de formação da renda, e, em sentido diametralmente oposto, uma cesta diversificada de produtos financeiros foi ganhando espaço" (SILVA, 20I3, p. 69).

É perceptível o contraste entre o modelo que se pretendeu superar a partir da década de 1970 e o novo, que se erigiu sob o signo da financeirização. Enquanto o primeiro, alicerçado na construção da sociedade salarial do pós-guerra, possibilitou um movimento de mobilidade social que deu densidade e dominância a um padrão de vida próprio dos estratos intermediários, o segundo mostra-se comprometido com o estabelecimento de uma disposição social mais polarizada e desigual.

Em meio a esse cenário, as transformações no modo de produção determinadas pelas inovações técnicas e organizacionais foram progressivamente corroendo a densidade do contrato de trabalho por tempo indeterminado e provocando a instabilidade do trabalho assalariado. Isso aconteceu junto com a terceirização e a polivalência, praticadas sob a navalha da ameaça recorrente do progresso técnico sobre 
a condição de emprego, que deram às empresas um poder importante de gestão da mobilidade do trabalho segundo seus interesses. Para os trabalhadores passou a ser fundamental defender a simples manutenção de emprego, e com isso as demandas relativas às condições de trabalho foram perdendo espaço ${ }^{12}$ (I2) (DEDECCA, 20IO; BRAGA, I997; KREIN, 200I).

Enquanto a produtividade crescia, via-se a fragilização do contrato e das relações de trabalho, junto com a desvalorização dos salários reais. Esse movimento foi reforçado pelas inovações organizacionais e técnicas da atividade produtiva, que permitiram às empresas realizarem a produção em países onde o trabalho manual é caracterizado pelos baixos salários.

Para Dedecca, a pressão por transformações no regime de regulação do mercado e nas relações de trabalho é reforçada pela desconfiança crescente quanto à capacidade de os Estados manterem as políticas de proteção trabalhista e social. Essa desconfiança se materializou, de modo contraditório, na legitimação social de importantes mudanças no regime de regulação. Essas mudanças validaram as premissas conservadoras favoráveis a uma menor intervenção do Estado nas relações econômicas e sociais (DEDECCA, 20IO, p. II).

De modo que se torna evidente, diante dos estudos realizados, que a "tendência” à financeirização se nutriu da depreciação do trabalho, pois exigiu queda de sua participação tanto na repartição primária do excedente produtivo quanto na repartição secundária via política pública. Assim, financeirização, fragmentação do trabalho e desigualdade social são partes de um mesmo conjunto e fundamentam o regime de regulação econômica e social construído a partir do final dos anos 1970.

A história mostra que esse processo não pode ser tido como um fato novo no progresso do sistema capitalista. Contudo, no movimento recente de desvalorização do trabalho, podemos notar que, infelizmente, a regressão na distribuição do excedente foi chancelada pelas instituições do Estado, e as mudanças no regime de regulação foram validadas por essas instituições. Todavia, mesmo parecendo preocupante que o Estado tenha contribuído para a consolidação da desvalorização do trabalho e para a financeirização da riqueza, é relevante que, por isso mesmo, percebamos que a renovação do próprio Estado e suas representações se torna a via principal para que uma nova fase de desenvolvimento regulado e combate à desigualdade seja estabelecida.

* Doutora em História pela Universidade Federal de Goiás (UFG).

E-mail: tamara.naiz@gmail.com

Texto recebido em maio de 2020; aprovado em junho de 2020.

12 Além da tendência de desvalorização dos salários, a desestruturação da base de trabalho assalariado pôs-se em movimento contínuo. O contrato de trabalho por tempo indeterminado foi dando progressivamente espaço para os contratos por tempo determinado e parcial. Entre os trabalhadores, essas alterações nas relações de trabalho implicaram uma crescente insegurança quanto ao futuro do mercado de trabalho, e também uma maior concorrência entre eles (DEDECCA, 2010; KREIN, 2001). 
BRAGA, José Carlos de Souza. Financeirização global: o padrão sistêmico de riqueza do capitalismo contemporâneo. In: TAVARES, Maria da Conceição; FIORI, José Luis (Org.). Poder e dinheiro: uma economia política da globalização. Rio de Janeiro: Vozes, 1997. p. 195-242.

Temporalidade da riqueza: teoria da dinâmica e financeirização do capitalismo. Campinas: IE-Unicamp, 2000. (Coleção Teses.)

CHESNAIS, François. A mundialização do capital. São Paulo: Xamã, 1996.

A teoria do regime de acumulação financeirizado: conteúdo, alcance e interrogações. Economia e Sociedade, Vol. 11, n. 1 (18), p. 1-44, jun (2002). Campinas: IE-Unicamp, 2002. Introdução geral. In: (Coord.). A mundialização financeira: gênese, custos e riscos. São Paulo: Xamã, 1998a, p. 11-33.

Mundialização financeira e vulnerabilidade sistêmica. In: (Coord.). A mundialização financeira: gênese, custos e riscos. São Paulo: Xamã, 1998b, p. 249-293.

A "nova economia": uma conjuntura própria à potência econômica estadunidense. In: CHESNAIS, F. [et al]. Uma nova fase do capitalismo? São Paulo: Xamã, 2003. p. 43-70.

DEDECCA, Claudio Salvadori. Racionalização econômica e trabalho no capitalismo avançado. Campinas: IE-Unicamp, 1999.

Trabalho, financeirização e desigualdade. Texto para Discussão, n. 174. Campinas: IE-Unicamp, 2010.

FIORI, José Luiz. Os moedeiros falsos. Petrópolis: Vozes, 1997.

FRONTANA, Andres Vivas. $\mathbf{O}$ capitalismo no fim do século $\mathbf{X X}$ : a regulação da moeda e das finanças em um regime de acumulação sob dominância financeira. 2000. Tese (Doutorado em economia na Faculdade de Economia, Administração, Contabilidade e Atuária -FEA da Universidade de São Paulo- USP), São Paulo, 2000.

GUTTMANN, Robert. A transformação do capital financeiro. Economia e Sociedade, Campinas, n. 7, p. 51-83, dez. 1996.

GUTTMANN, Robert. As mutações do capital financeiro. In: CHESNAIS, Francois (org). A mundializalação financeira: gênese, custos e riscos. São Paulo: Xamã, 1998.

HARVEY, David. A condição pós-moderna. São Paulo: Edições Loyola, 1992.

KREIN, José Dari. O aprofundamento da flexibilização das relações de trabalho no Brasil nos anos 1990. 2001. Dissertação (Mestrado em Economia Social e do Trabalho no Instituto de Economia da Universidade de Campinas - Unicamp), Campinas, 2001. 
MACIEL, David. A argamassa da ordem. São Paulo: Xamã, 2004.

Ditadura militar e capital monopolista: estruturação, dinâmica e legado. Lutas Sociais, São Paulo, v. 18 n. 32, p. 64-78, jan./jun. 2014.

MARX, Karl. O Capital. Livro 1: o processo de produção do capital. São Paulo: Nova Cultural, 1996. (Coleção Os Economistas.)

O Capital. Livro 3: o processo global de produção capitalista. Rio de Janeiro: Civilização Brasileira, 1974.

MOLLO, Maria de Lourdes. Capital fictício, autonomia produção-circulação e crises: precedentes teóricos para o entendimento da crise atual. Revista Economia, Brasília, set./dez. 2011, p. 475-493.

PAULANI, Leda Maria. Do conceito de dinheiro e do dinheiro como conceito. 1992. Tese (Doutorado em economia na Faculdade de Economia Administração e Contabilidade da Universidade de Campinas - Unicamp), Campinas, 1992.

- Quando o medo vence a esperança: um balanço da política econômica do primeiro ano do governo Lula. Crítica Marxista, Campinas, v. 19, p. 11-26, jul. 2004.

SILVA, Tamara Naiz da. De Sarney a Itamar Franco: Financeirização econômica, trabalho e direitos sociais no Brasil (1985-1994). Tese (Doutorado em História na Faculdade de História da Universidade Federal de Goiás - UFG). Goiania, 2020.

Financeirização econômica e mercado de trabalho no Brasil. 2012. Dissertação (Mestrado em História na Faculdade de História da Universidade Federal de Goiás - UFG), Goiânia, 2012.

TAVARES, Maria da Conceição. A retomada da hegemonia norte-americana. In: FIORI, José Luis (Org.). Poder e dinheiro: uma economia política da globalização. Rio de Janeiro: Vozes, 1997. p. 27-53.

; FIORI, José Luis. (Des)ajuste global e a modernização conservadora. Rio de Janeiro: Paz e Terra, 1993.

TAVARES, Maria da Conceição; MELIN, Luiz Eduardo. Pós-escrito 1997: a reafirmação da hegemonia norte-americana. In: TAVARES, Maria da Conceição; FIORI, José Luis (Org.). Poder e dinheiro: uma economia política da globalização. Rio de Janeiro: Vozes, 1997. p. 55- 86.

TEIXEIRA, Rodrigo Alvez. Dependência, desenvolvimento e dominância financeira: a economia brasileira e o capitalismo mundial. 2007. Tese (Doutorado em Teoria Econômica pela Faculdade de Economia, Administração e Contabilidade da Universidade de São Paulo - USP), São Paulo, 2007. 